\title{
See it with my eyes: artificial stream research communicated by an artist
}

\author{
Anne Rinn ${ }^{1}$, Christoph Kivelitz and Rüdiger Berghahn²
}

\begin{abstract}
Artist Anne Rinn takes the reader on an excursion to an indoor and outdoor artificial pond and stream mesocosm system. This device was constructed and put into operation in 2001 in order to carry out scientific investigations concerning the aquatic environment, with the main focus on fate and effects of pollutants. Both technical features of the facility and the work and ideas for scientists and technicians were translated by her into an art exhibition which also included a film. This report on the project consists of two different text parts, one by the third author, who is an aquatic toxicologist, and one by the second author, an art historian. Their different backgrounds are reflected in different thinking and styles of expression. The text is rounded off by the photos of the first author, the artist.
\end{abstract}

Keywords: Nature, Simulation, Art, Film, Exhibition

\section{Impetus}

The German Federal Environment Agency runs a site for aquatic simulation in the very south of Berlin, which also includes a set of outdoor and indoor artificial pond and stream mesocosms (FSA) for research in aquatic toxicology [1,2]. Up to the present, 30 studies were carried out in that facility during the last 10 years [1]. The results have been popularized via the official homepage, guided tours, conference posters [1], talks and sessions, scientific journals [1], magazines, newspapers, and TV features. Seeking further means to reach a wider audience apart from ecotoxicological professionals and people interested in natural sciences, and reflecting on the positive experience which had been gained previously in cooperation between science and art [3], the FSA team decided to support the idea of the artist Anne Rinn [4] to stage an exhibition and to create a film entitled 'Keep Your Boots Muddy.' Both exhibition and film pivot on the triangle nature-simulation-art, with simulation creating artificial nature (Figure 1). Taking up the triangle idea, this article is structured as a report on the project, consisting of three parts, namely the framing text of the third author, who is an aquatic toxicologist, fragments

\footnotetext{
* Correspondence: ruediger.berghahn@uba.de

Deceased

${ }^{2}$ German Federal Environment Agency, Schichauweg 58, 12307, Berlin,

Germany

Full list of author information is available at the end of the article
}

of the opening speech to the exhibition held by the second author, an art historian, and the photos of the exhibition by the first author, an artist.

\section{Exhibition and film}

Both the film (Figure 2) [5] and the exhibition 'Keep your boots muddy' (Figures 3,4,5,6,7,8,9,10,11,12) view the FSA with different eyes, not those of a natural scientist or an engineer but with the eyes of the artist. In the film, pictures of the device and the diverse work activities were set to offstage voices of different FSA team members (metal worker, technicians, and scientists), explaining their tasks and also their philosophies. The viewer has the impression that they are talking to themselves. This open inner dialog allows us to gain insight into their conventions and repetitive work processes and to understand how intuition might often be a leading force in science.

In his opening speech (for the full German version see the Additional file 1 to this publication), the art historian tried to bridge the gap between the communication in the world of the artists and that of the scientists straight from the beginning, and he had good reasons to do so. As is often the case with research units, the FSA is fairly isolated from the public, not only spatially but also mentally, since research is generally considered to be too complicated for non-scientists or members of other disciplines by both scientists and the public. The

\section{它}



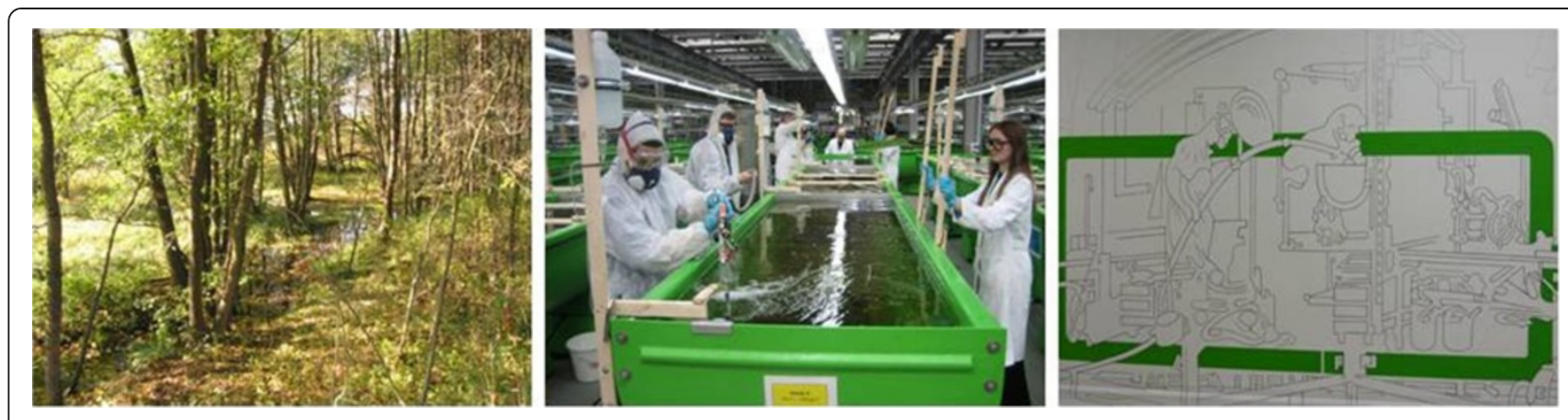

Figure 1 Nature-simulation-art.

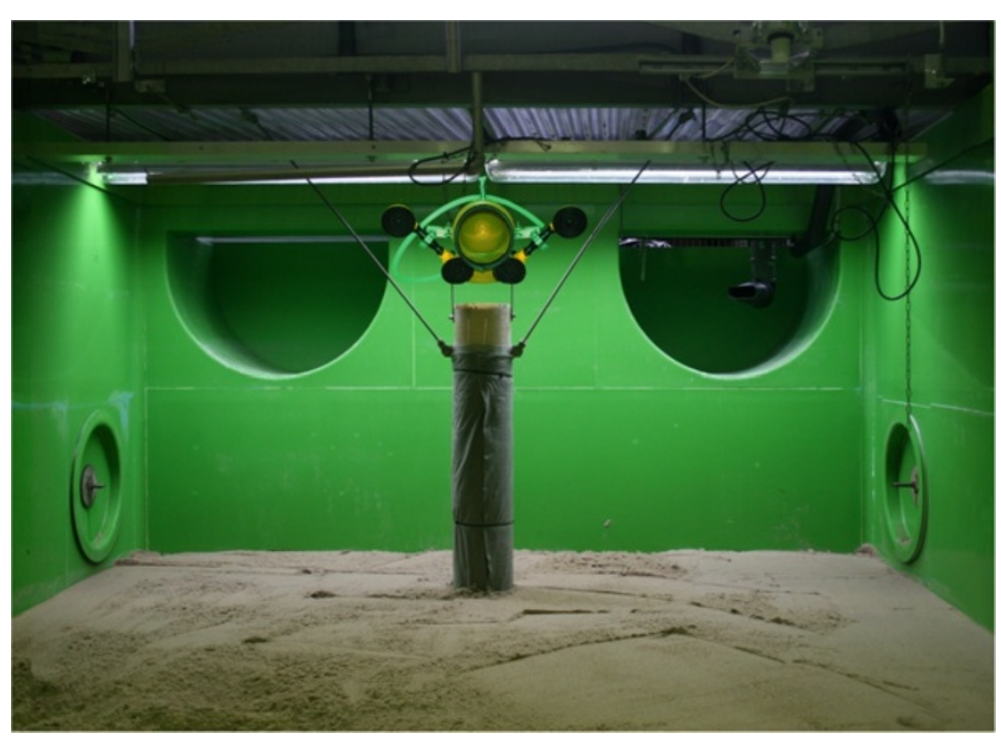

Figure 2 Screenshot from the film (http://bit.ly/Keep_Your_Boots_Muddy), which was also used as invitation card for the exhibition.

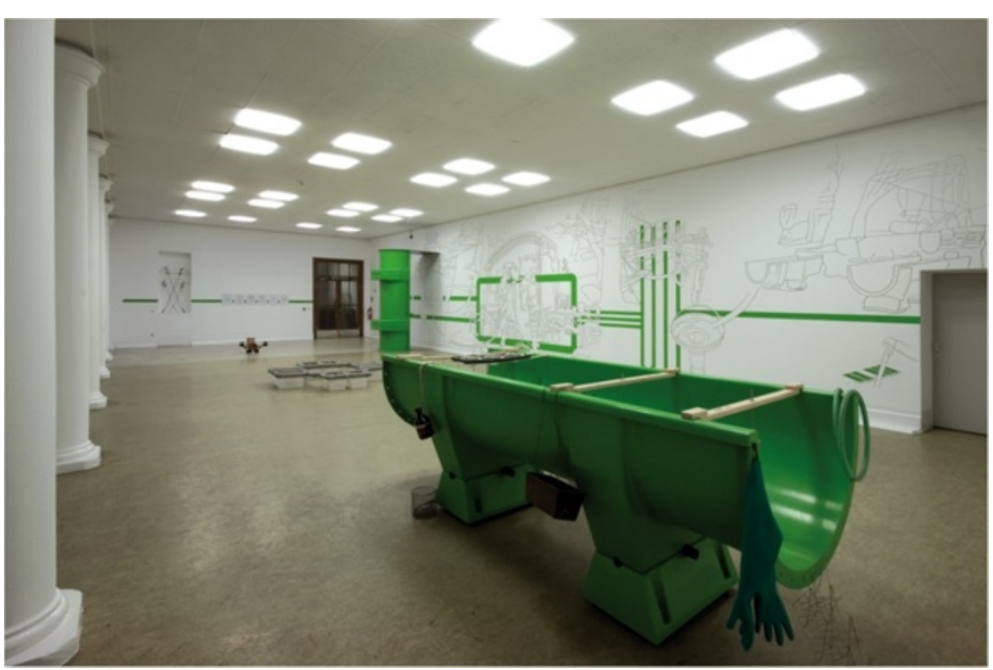

Figure 3 Exhibition hall. 


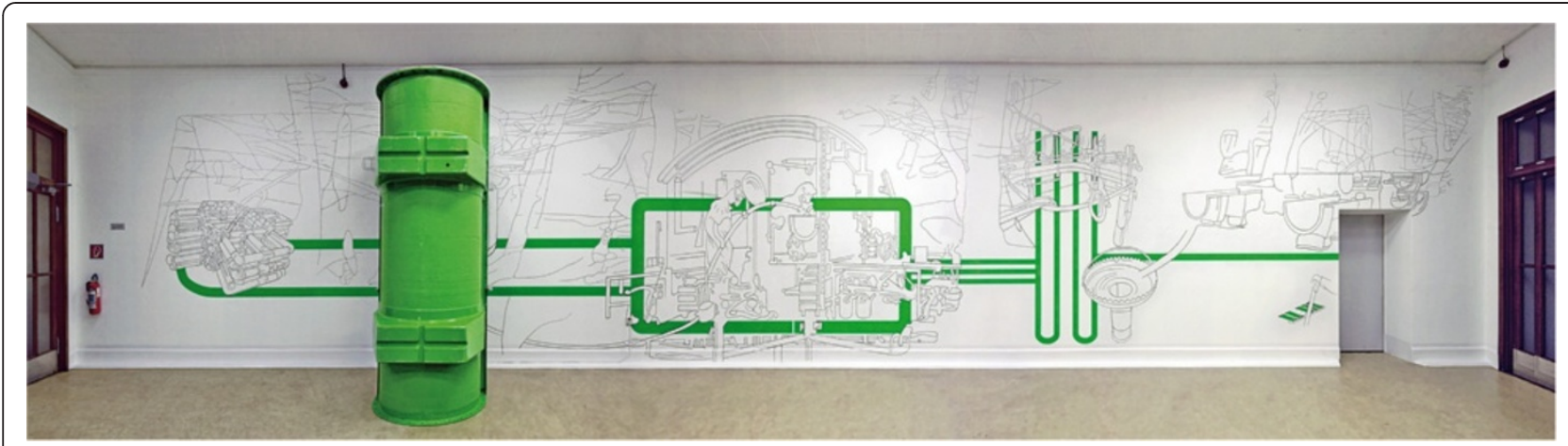

Figure 4 Wide shot of the wall painting with upright-positioned artificial stream module.

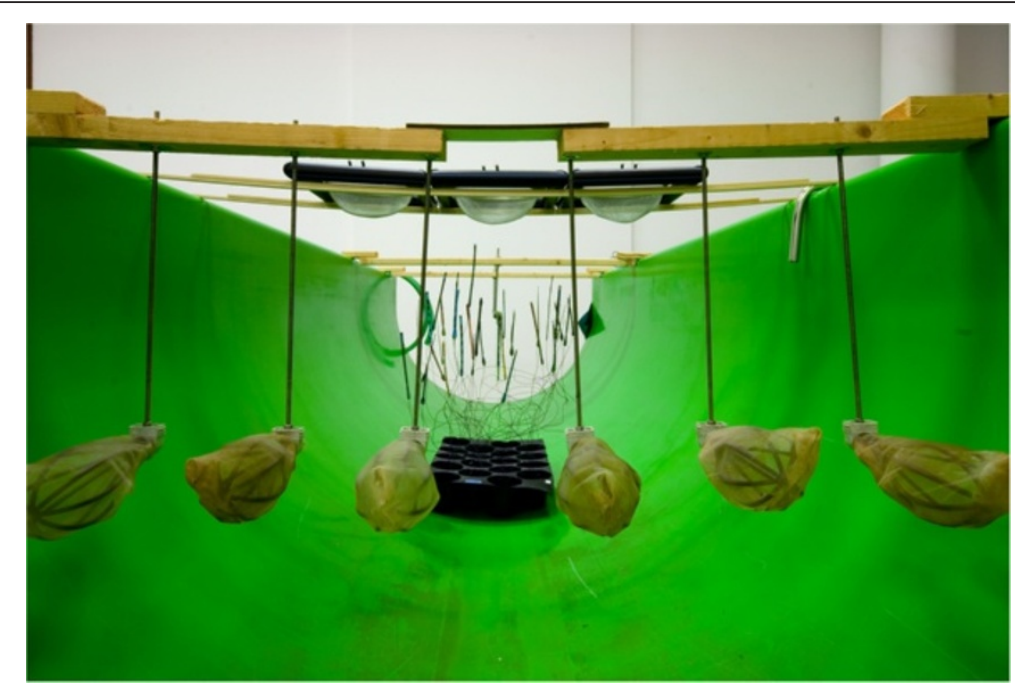

Figure 5 Cages (front) for in situ exposure of invertebrates and litter in the artificial streams.

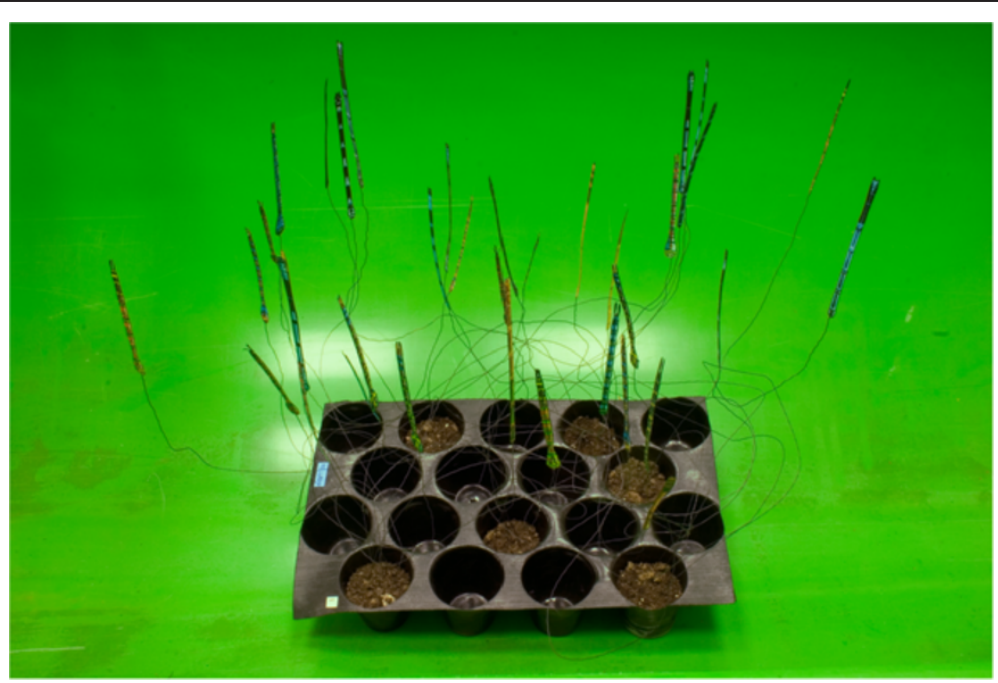

Figure 6 Plant pot unit with artificial objects akin to bodies of dragon flies. 


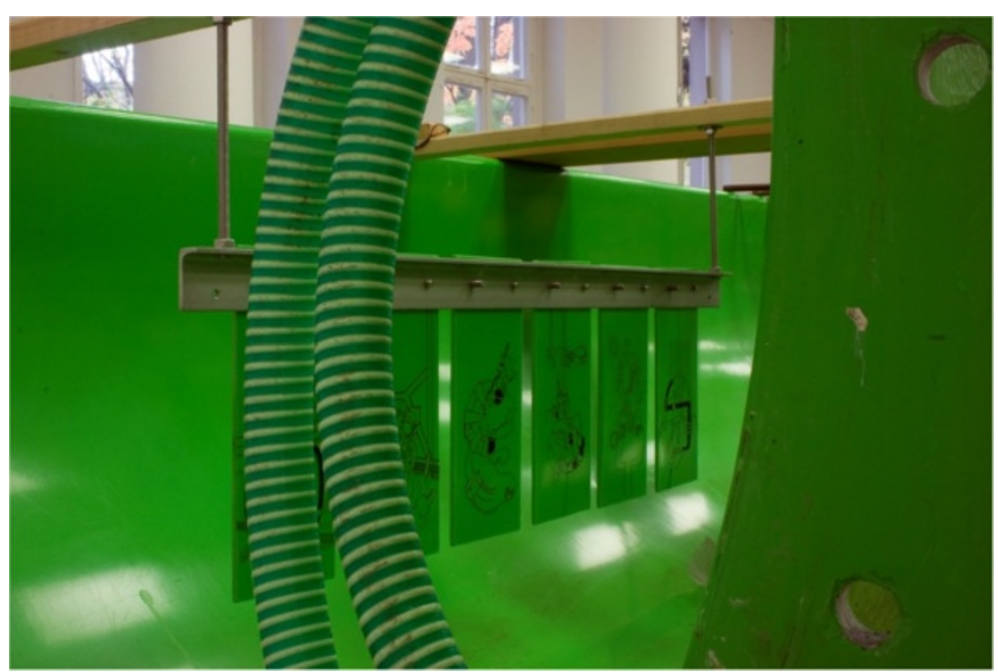

Figure 7 Drawings on fiberglass-reinforced polyester plates to measure periphyton growth.

fundamental differences in the perception of the world and, in particular, of nature between social communities and cultures as well as scientific and technical disciplines (see e.g. [6]) and even among the diverse natural sciences is among the other things reflected in expert language. To come along on top, this professional jargon may be riddled with abbreviations for insiders, as is definitely the case in ecotoxicology. Recent cautionary examples are NOAEL for 'No-Observed-Adverse-Effect Level' and REACH TGD for 'Technical Guidance Document in the EU regulatory framework for the Registration, Evaluation and Authorization of Chemicals.' Many curious people, who dare to cross the border to a foreign society of any kind, may be shocked, disgruntled, or bored by their new experience. Some, however, may become fascinated, grab some information, and translate to others what goes on behind the curtain. This transfer will become a challenge of increasing importance in our more and more fragmented social life. As in predator-prey relationships, the first step in the transfer process is the encounter (see e.g. [7]), which is density-dependent and accidental and is a matter of likelihood, which can be raised by different means. Regardless of who is in this case the predator and who is the prey, the next step would be attraction and the essential crossing of the border to the foreign world. This is why in both exhibition and film, the recipient is not only getting information but taken by the hand on a guided tour.

Understandably, scientists generally behave most earnestly in order to avoid everything that may question their competence and reliability. They do sound science and refrain from appearing too colorful but tend instead to be rather modest and shy. In combination with expert language, these features may cause an even greater distance and appear boring to the public. Against this background, the idea of the film was to approach the public by demonstrating that the job of the technicians and scientists is as much related to essential questions as any other human activity and that 'these people' are in a way 'just like you and me.' For amplification of this impression, it was important that the interviewer could spontaneously ask questions like

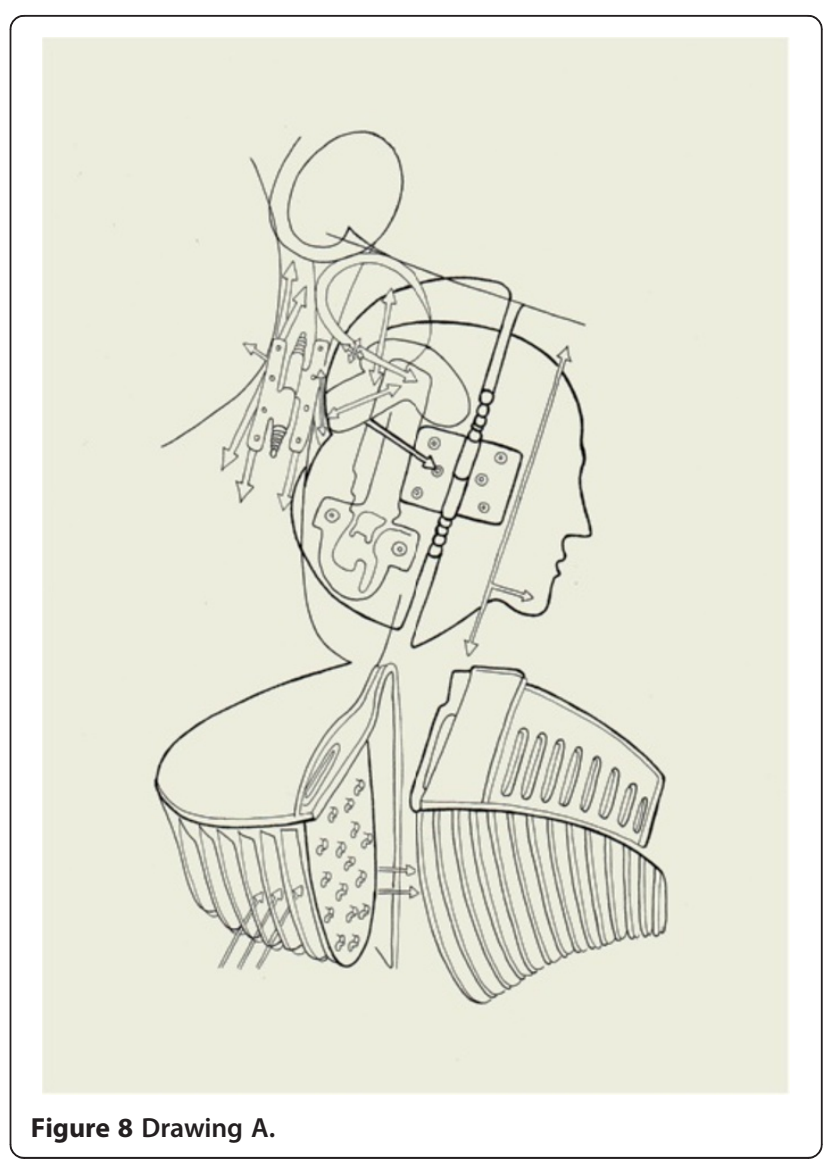




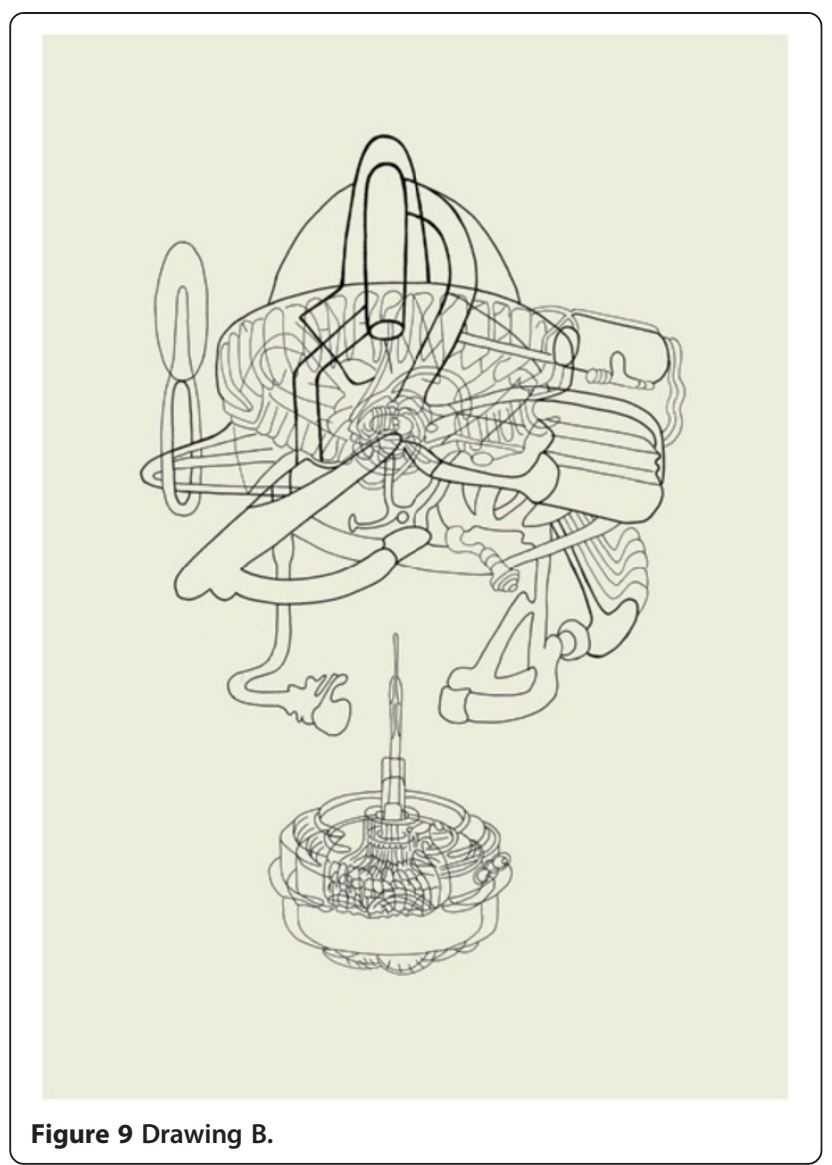

'What is going round in your head when you do your job?' The ones who were at that time involved in more repetitive work answered intuitively, whereas the others had to cope with the difficulties in finding easy explanations for complex relationships. It was also crucial that the recordings were cut by the artist without any restrictions or exertion of influence by both the protagonists and the Federal Environment Agency. Thus, a high level of authenticity and 'human factor' was achieved, the use of expert language widely circumvented, and at the same time the curiosity of the recipient was kept at a high level. Concomitant to this, of course, the risk was taken of being criticized by members of the scientific community for certain broad statements and potentially negative reactions by the public.

Last but not least, there is also a certain touch of romance in technically sophisticated devices [1] (Figures$10,11,12$ ) which may attract and fascinate people. This inherent nature of technical facilities, machines, and products is a rich source of inspiration for artists and therefore focused on in both the exhibition (Figures$2,4,5,6,7,8,9)$ and film. Nevertheless, the value of such art is inherently and always under public debate. Art historians may help to bring people closer to art by providing an understandable context. For the art presented here, this context was given by the art historian as follows:

The artificial stream and pond system of the German Federal Environment Agency is certainly an unusual setting for a contemporary art exhibition. The simulator plant is a gigantic laboratory that reproduces the conditions of natural waterways. Here, scientists study changes and disruptions of natural habitats in order to determine their impact and explore possibilities of regeneration...

...Anne Rinn describes her art project in this futuristic setting as an excursion into another world. The first step of the project was indeed systematic research in an effort to understand the

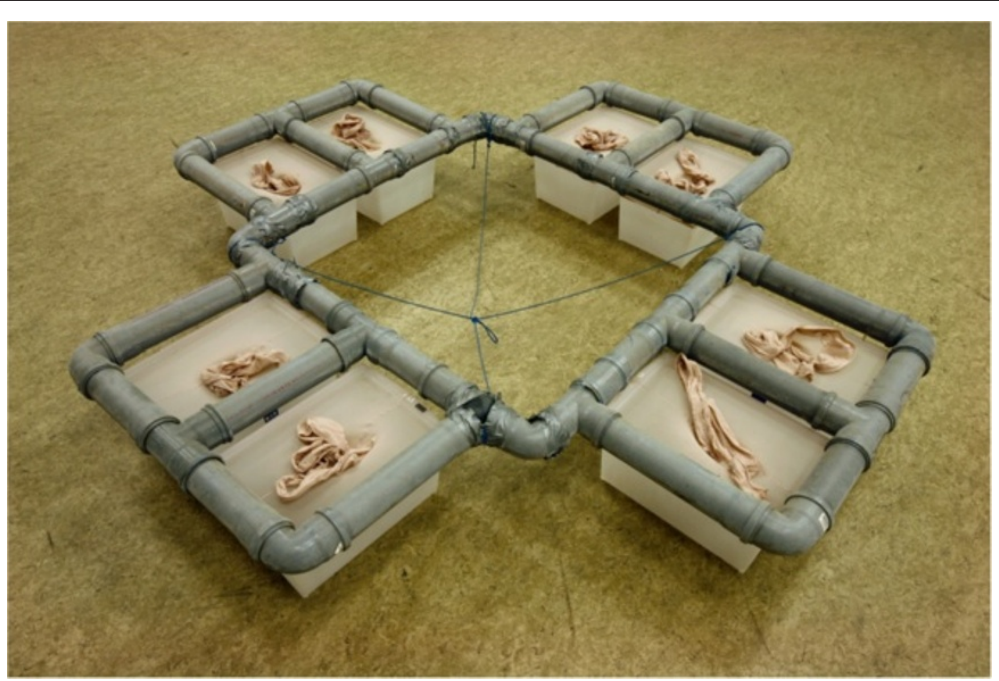

Figure 10 Floating aquaria for microcosm experiments in the field. 


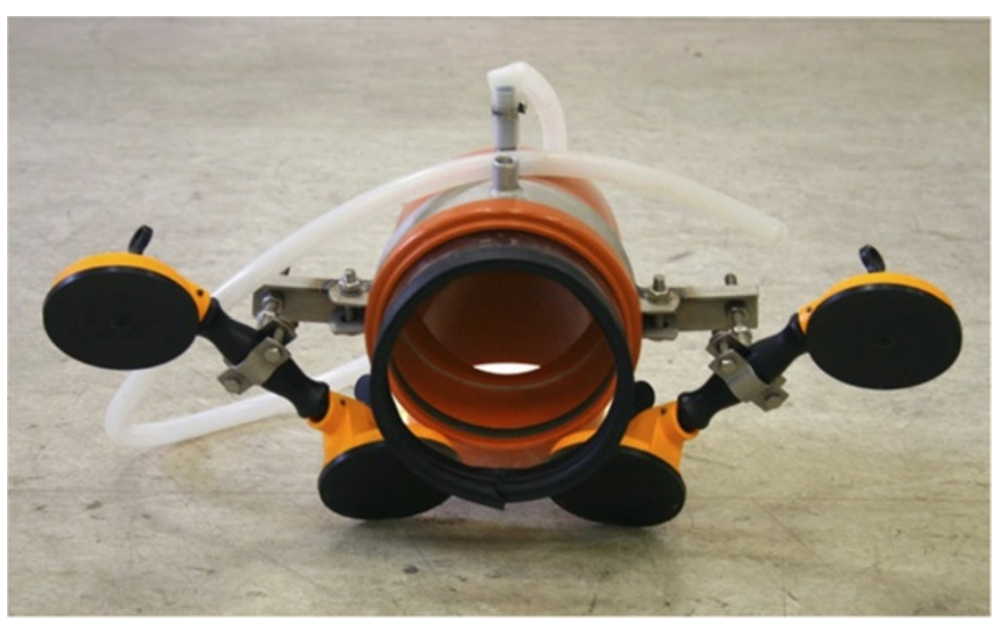

Figure 11 Self-built prototype of a special device for sampling the walls of the artificial streams.

everyday procedures, objectives and behavior patterns of the people working here. Her artistic undertaking therefore has, to a certain extent, a documentary aspect. This is reflected particularly clearly in the film, which describes various sequences of the scientific work and backs them with appropriate passages taken from interviews with staff. But Anne Rinn goes far beyond this purely documentary aspect. She wants to do more than understand the seemingly cryptic work of the scientists merely for her own benefit: she also wants to convey its social and cultural significance to a broader public and thus attempts to span the distance between ourselves and science that we have come to perceive as seemingly unbridgeable....

...In the film, the statements selected from the interviews with researchers show clearly that their attitude towards the simulator is as complex and contradictory as their attitude towards nature itself. On the one hand, they are aware that they themselves are the inventors and creators of the entire system. On the other, however, they also realize that it functions as an organism in its own right, one that has detached itself from them and has developed its own dynamics. At some point, humanity has to submit to the forces it has set free, find a modus vivendi with them - while at

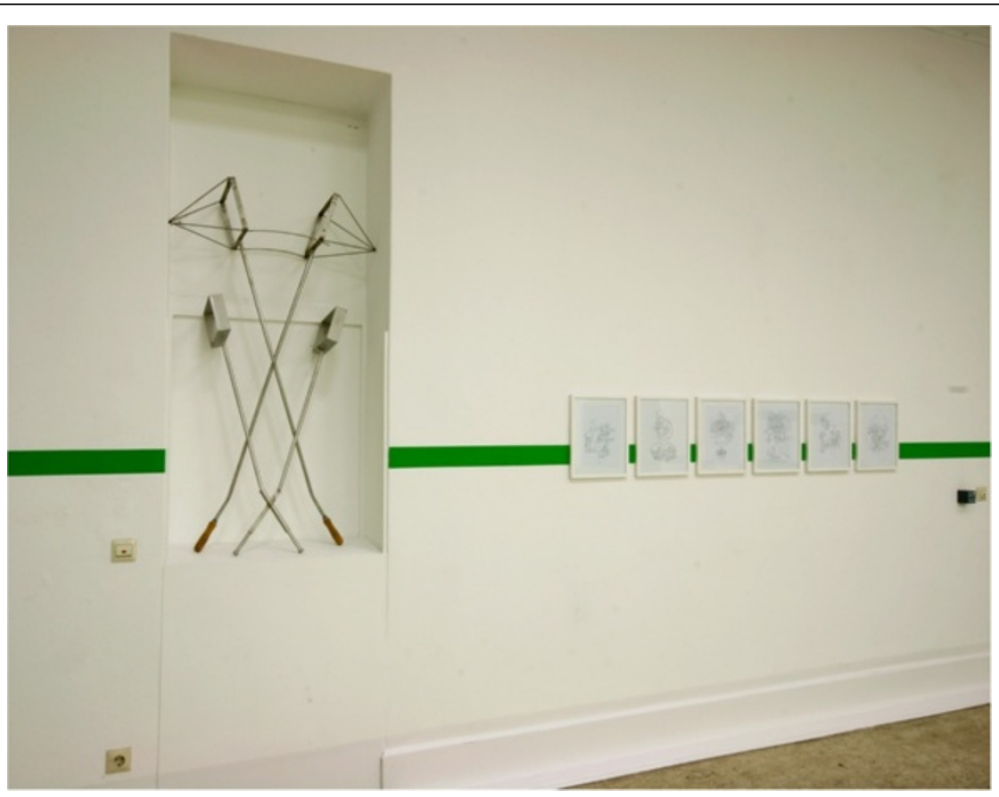

Figure 12 Frames of spoon nets. 
the same time it stands outside and above them, with the power to disrupt, change and analyze the system, and ultimately even to destroy it. The relationship of humans with nature, from which they have emerged as biologically determined beings, is similarly paradoxical. As human beings, we depend on the continued existence and harmonious order of nature, and yet we dissociate ourselves from it, alienate ourselves from it, try to rise above it, fully aware of the danger of destroying our habitat....

...In the central mural - which, with its prominent contour lines, resembles an engineer's technical drawing - the artist suggests the rough outlines of segments of the equipment, linked by lines, pipes and tubes. Vaguely discernible in the mesh of this complex network are a few of the scientists in their protective clothing - less as acting entities, more as integral components of the system. In a way, Anne Rinn has shifted the scientific activity to a kind of metalevel, a reflecting surface for a multirefracted image of man, science and nature. In itself, the simulator is already a structure which parallels nature, a system intended to imitate a natural landscape. And now, this parallel construction itself has become the subject matter of Anne Rinn's work, and with it the relationship of the simulator to its natural model and the position of human beings with regard to the two reference planes....

...In the space made available to her, Anne Rinn takes up fragments of the simulation system in order to isolate them, in her installation, as sculpture-like artifacts that are dissociated from their original context ... In this new arrangement, the technical machinery, which has become banal and commonplace for the scientists and technicians, gains a poetic quality that can no longer be reduced solely to its functional significance. Anne Rinn's work brings to light an added value that can be better grasped on an emotional and intuitive level than as something purely rational and logical. She addresses a level of awareness that seems to be diametrically opposed to that of the scientist, one that nevertheless affects a significant part of human thought and knowledge, and thus represents an essential quality of our human existence. With her installation, the artist takes the viewer into a kind of parallel structure that simulates the actions of the scientists on a different level. Viewers get the impression that they have advanced to the very center of scientific research. But here, indeed, above and beyond the actual objectives of the simulator - to respect and preserve nature in its harmonic order - viewers come to sense that human beings simply cannot design or imitate nature in its eternal flow. All we can do is follow the eternal quest of achieving this goal, as a scientist, as an artist, or in the interaction of these seemingly mutually exclusive methodological approaches (end of citation).

\section{Dissemination}

The German two-minute version of the film was used as a teaser for the exhibition on YouTube from November to December 2010. It was viewed more than 500 times. Around that time also, a significant increase in the visits to the FSA homepage was detected. The opening speech induced very lively discussions among the 80 participants at the start of the exhibition and the exhibition was a success even though the location in Berlin was not optimal with regard to accessibility with local transport and opening hours. Moreover, the film was presented at the German 28th Kasseler DokFest 2011 [8] and before a full audience at the world meeting of the Society of Environmental Toxicology and Chemistry (SETAC) 2012 in Berlin. It has also routinely been shown as an introduction to public visitors of the FSA, for example, on open days. Up to now, it was a crowd pleaser for both laypersons and scientists. Nevertheless, new and also critical comments are always welcome.

\section{Conclusion}

The combination of science and art may help to open up ecotoxicological issues to the wider public. If this is done by means of contemporary media in a popular way, one can avoid the risk to just move from one ivory tower to the next and may create a win-win situation for both science and art.

\section{Additional file}

Additional file 1: Opening speech. Full German version of the opening speech held by Christoph Kivelitz.

\section{Competing interests}

The authors declare that they have no competing interests.

\section{Authors' contributions}

AR did the art, made the film, the photos, and the interviews and drafted the manuscript together with RB. CK held the opening speech of the exhibition. All authors read and approved the final manuscript.

\section{Acknowledgments}

The authors thank Nicole Gentz for the translation of the opening speech held by Christoph Kivelitz, Gabriele Coan for translating the subtitles for the film, Susan Beddig for improving the English of the manuscript, and three anonymous referees for critical, encouraging, and helpful comments.

\section{Author details}

${ }^{1}$ Atelier, Langhansstraße 7A, 13068, Berlin, Germany. ${ }^{2}$ German Federal Environment Agency, Schichauweg 58, 12307, Berlin, Germany. 


\section{References}

1. Artificial pond and stream system of the German Federal Environment Agency. http://www.umweltbundesamt.de/wasser-und-gewaesserschutz/fsa.

2. Mohr S, Feibicke M, Ottenströer T, Meinecke S, Berghahn R, Schmidt R: Enhanced experimental flexibility and control in ecotoxicological mesocosm experiments - A new outdoor and indoor pond and stream systems. Environ Sci Pollut Res 2005, 12:5-7.

3. Mohr S: Dialog zwischen Wissenschaft und Kunst. BIOspektrum 2007, 4:462.

4. Anne Rinn. www.anne-rinn.de.

5. Anne Rinn: Keep your boots muddy. http://bit.ly/Keep_Your_Boots_Muddy.

6. Precht RD: Die Kunst, kein Egoist zu sein. München: Goldmann; 2010.

7. Leggett WC, Deblois E: Recruitment in marine fishes: is it regulated by starvation and predation in the egg and larval stages? Neth J Sea Res 1994, 32:119-134.

8. Filmladen. www.filmladen.de.

doi:10.1186/2190-4715-25-13

Cite this article as: Rinn et al: See it with my eyes: artificial stream research communicated by an artist. Environmental Sciences Europe 2013 25:13.

\section{Submit your manuscript to a SpringerOpen ${ }^{\circ}$ journal and benefit from:}

- Convenient online submission

- Rigorous peer review

- Immediate publication on acceptance

- Open access: articles freely available online

- High visibility within the field

- Retaining the copyright to your article 